\title{
NATURAL HISTORY AND BEHAVIOR OF TWO SPECIES OF MACROHALTICA (COLEOPTERA: CHRYSOMELIDAE)
}

\author{
By W. Eberhard ${ }^{1,2}$, R. AchoY ${ }^{2}$, M. C. MARIN ${ }^{2}$, AND J. UGALDE ${ }^{2,3}$

\section{INTRODUCTION}

The genus Macrohaltica and the allied genus Altica have approximately 30 described species in Central America and perhaps 200 or more worldwide (R. White pers. comm.). Larvae and adults often feed on onagraceous and ericaceous plants (Scherer 1969, Phillips 1977a), though other plants are also utilized (Woods 1918, Balsbaugh and Hays 1972, Phillips 1977a, Barstow and Gittins 1973, LeSage 1990). Some species of Macrohaltica are considered secondary pests of crops in Costa Rica (King and Saunders 1984). Some species are difficult to distinguish morphologically (Phillips 1977b), and both parthenogenesis and interspecific hybridization are known (Phillips 1977a, 1979).

This paper describes aspects of the natural history and behavior of a pair of species in the central highlands of Costa Rica, a metallic blue species $M$. jamaicensis (hereafter $M . j$.), and an apparently undescribed metallic purple species (hereafter $M$. sp.). The beetles frequently attract attention because they aggregate, sometimes in masses of up to several thousand individuals. A second striking trait is that some aggregations include individuals of both species, and cross-specific male-female pairs are common in such aggregations.

\section{MATERIALS AND MethodS}

Observations were made over a span of nine years, during which time we saw many tens of thousands of beetles in the field, and raised thousands in captivity. The behavior of beetles in four aggregations was observed in detail:

Aggregation I - both species on Ludwigia octovalvis (Onagraceae) plants near San Antonio de Escazu, el. 1300 m, 27

\footnotetext{
${ }^{1}$ Smithsonian Tropical Research Institute

2 Escuela de Biologia, Universidad de Costa Rica, Ciudad Universitaria, Costa Rica

${ }^{3}$ Instituto Nacional de Biodiversidad, Santo Domingo de Heredia, Costa Rica

Manuscript received 11 January 1993.
} 
June-13 July 1983). In this and other field observations, adults of $M$. sp. were identified by their purple color; since F1 hybrids between the species are also purple (R. Achoy unpub. thesis), these identifications are somewhat uncertain. Nevertheless hybrid individuals (distinguished by genitalic characters) are uncommon in the field (Eberhard and Ugalde in prep.);

Aggregation II - M. $j$. on Cuphea sp. (Litraceae) plants near the edge of a lawn near San Vito de Java, el. 1000 m, 23-25 Jan. 1987;

Aggregation III $-M$. sp. on low grass in a pasture near Monteverde, el. $1300 \mathrm{~m}, 14-15$ Feb. 1985; and

Aggregation IV $-M$. sp. on various plants along approximately $50 \mathrm{~m}$ of a roadside above San Antonio de Escazu, el. $1400 \mathrm{~m}$, Feb-June, 1992. These and other sites mentioned in the text are shown in Fig. 1.

All beetles in Aggregation I were counted on 12 nights. Each night all unmarked pairs of males and females were marked on the dorsal surface with airplane enamel (two spots for males, one for females). Unmarked solitary beetles were not marked.

Beetles were raised in captivity in San José with ambient temperatures and light cycles. Larvae were fed freshly cut leaves in petri dishes, and adults were fed either the same or kept in plastic bags on branches of potted food plants. When larvae ceased feeding and began wandering, they were placed in containers with soft soil where they could pupate.

Experiments on preferences for pupation substrates were performed as follows. An approximately cylindrical plastic cup (8.8 $\mathrm{cm}$ in diameter at the mouth) was placed in the center of an approximately cylindrical, larger plastic container $(16.0 \mathrm{~cm}$ in diameter at the mouth). The cup was filled to the brim with one substrate and set in the center of the larger container, which was then filled to the brim of the cup with the other substrate. Larvae placed on the surface thus had access to both types of substrate $\left(60.8 \mathrm{~cm}^{2}\right.$ of the substrate in the cup, $140.3 \mathrm{~cm}^{2}$ of that in the larger container). Neither type of soil was compacted. After the larvae (30-40 per repetition) had disappeared underground, the smaller container was removed from the larger, and the numbers of adults reared from each were recorded. In replica experiments substrates in the larger and smaller containers were reversed.

Voucher specimens of adult beetles are deposited in the U. S. National Museum, the British Museum (Natural History), and the 


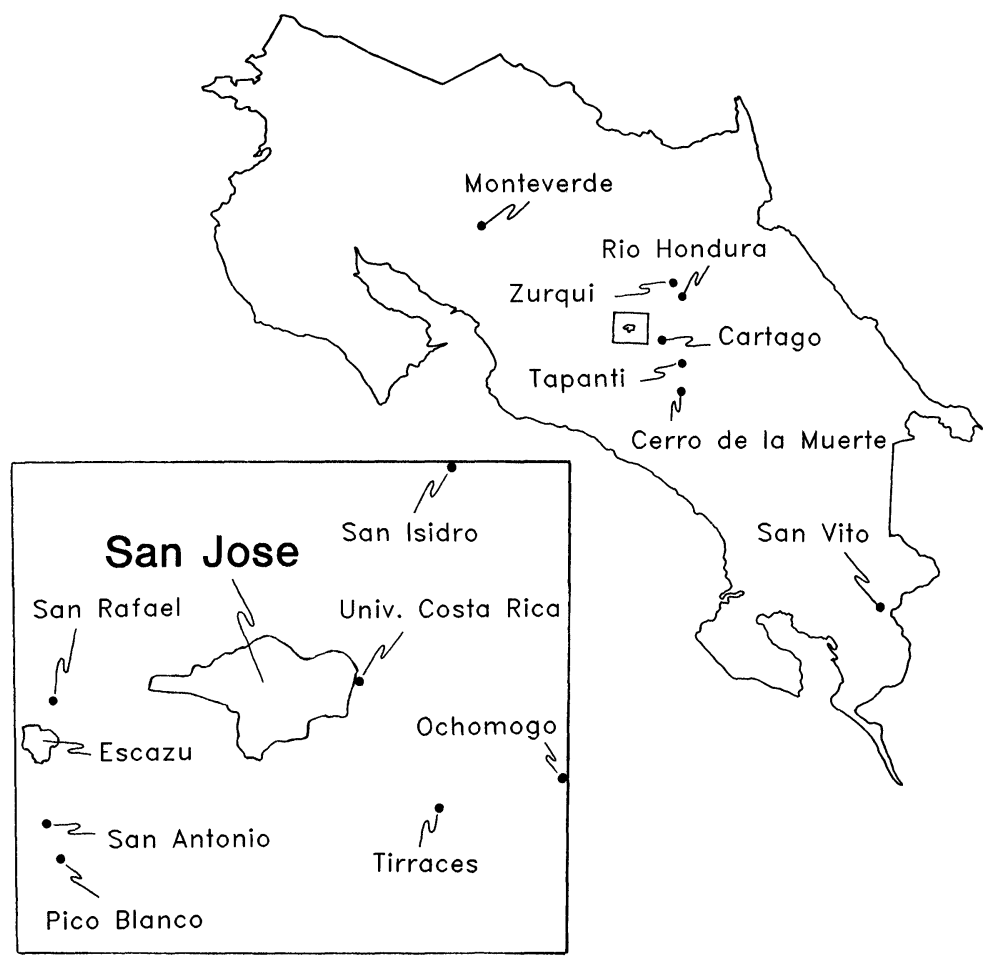

Fig. 1. Map of study area, showing sites mentioned in the text.

Museo Nacional de Costa Rica housed at the Instituto Nacional de Biodiversidad. Vouchers of the plants are in collections of the Missouri Botanical Garden, St. Louis, MO and the Escuela de Biología of the Universidad de Costa Rica.

Unless noted otherwise, all statistical tests were two-tailed Chi squared tests. Averages are followed by one standard deviation.

\section{RESULTS}

\section{Altitudinal Range}

The altitudinal ranges of the two species differed. The highest and lowest sites at which we found $M$. sp. were approximately $2300 \mathrm{~m}$ on Cerro de la Muerte, and about $1000 \mathrm{~m}$ near San Rafael de Escazu; $M$. $j$. was absent at higher elevations, occurring from 
San Josecito de San Isidro de Heredia and above San Antonio de Escazu (both about $1400 \mathrm{~m}$ ) to San Rafael de Escazu (1000 m).

\section{Life Cycle}

Both species were raised from egg to adult in captivity. Approximate durations of immature life stages were 5 days for the egg, 21 for the larva, and 14 for the pupa, but durations of the larval stage varied somewhat for both species on different host plants (Table 1). The longest adult life in captivity was 94 days for a female $M$. $j$. (a F1 hybrid female lived 99 days). Eggs were about $1.2 \mathrm{~mm}$ long, oval in shape, and yellowish in color. They did not have the fecal streak found on the eggs of some Altica spp. (Woods 1917, Phillips 1977a). Each egg was covered with a highly reticulate mesh of a white, somewhat extensible, adhesive material. When the egg was dry this covering gave it a white color. When a group of 50 newlylaid eggs $(<24 \mathrm{hr}$ old) was tasted, they produced a burning sensation similar to that of the larvae (below) but weaker.

Oviposition behavior of $M$. $j$. was observed in captivity. The female made repeated brief, apparently exploratory extensions of her genitalia against the substrate before ovipositing. The pair of coxites, which bear setae which are probably chemosensory and/or mechanosensory in function (Phillips 1978), projected rearward beyond the tip of the ovipositor with each extension.

Table 1. Larval weight at maturity, and average development time for larvae raised on two different food plants. $(j .=M$. jamaicensis; $\mathrm{sp} .=M$. $\mathrm{sp}$.). Numbers in parentheses are total number of larvae weighed, and number of groups of larvae weighed. Larvae from all crosses were significantly lighter when raised on $G$. insig$n i s$ ( $<0.01$ with Kruskal-Wallis using groups of larvae). Larvae of $j . \times j$. cross raised on $G$. insignis were significantly lighter $(\mathrm{P}<0.005$ with Kruskal Wallis) than those of all other species.

\begin{tabular}{|c|c|c|c|c|c|}
\hline & & \multicolumn{2}{|c|}{ Ludwigia octovalvis } & \multicolumn{2}{|c|}{ Gunnera insignis } \\
\hline $\begin{array}{l}\text { Cro } \\
\text { female }\end{array}$ & male & $\begin{array}{l}\text { larval wt. } \\
\text { at maturity } \\
(\mathrm{mg})\end{array}$ & $\begin{array}{l}\text { development } \\
\text { time } \\
\text { (days) }\end{array}$ & $\begin{array}{l}\text { larval wt. } \\
\text { at maturity } \\
(\mathrm{mg})\end{array}$ & $\begin{array}{c}\text { development } \\
\text { time } \\
\text { (days) }\end{array}$ \\
\hline j. $\quad \times$ & $j$. & $45.3 \pm 2.2(533,8)$ & 14.3 & $10.6 \pm 0.2(3,2)$ & 40.3 \\
\hline sp. $\times$ & sp. & $42.3 \pm 3.8(326,13)$ & 21.6 & $30.2(144,7)$ & 34.7 \\
\hline j. $\times$ & sp. & $42.9 \pm 2.2(131,5)$ & 17.5 & $36.6 \pm 1.9(111,5)$ & 29.3 \\
\hline sp. $\times$ & $j$. & $45.9 \pm 2.0(64,4)$ & 16.4 & $34.7 \pm 0.9(78,4)$ & 29.4 \\
\hline
\end{tabular}


Eggs were found on the leaves of all three genera of host plants. Those of $M$. sp. on the large $G$. insignis leaves, which were up to more than $1 \mathrm{~m}$ in diameter, were usually solitary, each alongside a vein of the leaf; in a sample of 728 eggs, there was one group of 9, 3 of 3, 20 of 2, while all the other 670 eggs were not within $.5 \mathrm{~mm}$ of another egg (average group size $=1.05 \pm 0.37$ ). In contrast, the eggs of $M . j$. were much more often grouped (av. group size = $10.9 \pm 10.9$, range $1-59, \mathrm{n}=1341$ ) on the thinner and much smaller leaves of Ludwigia octovalvis (about $1 \mathrm{~cm}$ wide). Eggs of $M . j$. on L. octovalvis were nearly always on the underside of the leaf (70 of 74 groups). In captivity $M . j$. also laid eggs in tight spaces such as the crack between the top and bottom of a petri dish.

Eggs of $M . j$. generally failed to hatch unless they were quite humid. Thus eggs laid on leaves of potted $L$. octovalvis plants in the lab (where neither rain nor dew wet the eggs) late in the wet season (Oct. 1991) often failed to produce larvae (only $21.9 \%$ of 2061 eggs in 54 groups hatched); at least one egg hatched in only 16 of 54 groups laid by 5 females (branches with eggs were enclosed in small plastic sandwich bags with many small holes). In the early dry season (Nov. 1991) hatching success was even lower ( 16 of 128 groups laid by 12 females, $\mathrm{p}<0.01$ ). In contrast, when leaves on which eggs had recently been laid were placed on filter paper or paper napkins saturated with water in small, culture dishes, hatching success was much higher ( $79 \%$ of 506 eggs; 39 of 39 groups had at least one egg hatch) $(\mathrm{p}<0.001$ compared with groups of eggs on leaves).

Survivorship of eggs and larvae on plants where adults were aggregated was probably reduced. Aggregations of adults sometimes completely stripped $G$. insignis leaves and entire Cuphea and Ludwigia plants (Fig. 2), so eggs could be consumed along with the plant. We observed captive adults eating eggs laid on the walls of petri dishes. Larvae which eclosed on plants with aggregations of adults also ran the risk of not having adequate food. Females of at least $M$. sp. tended to oviposit on leaves where adults were not aggregated. Inspection of 16 pairs of $G$. insignis leaves, one with an aggregation of adults and the other the nearest relatively uneaten leaf of the same plant, showed that even though $M$. sp. beetles were seldom seen away from aggregations, the densities of eggs (eggs $/ \mathrm{cm}^{2}$ ) were lower on the occupied leaves: average densities were $4.28 \pm 7.01 / \mathrm{cm}^{2}$ (range $0-26.4$ ) vs. $6.71 \pm 6.96 / \mathrm{cm}^{2}$ (range 

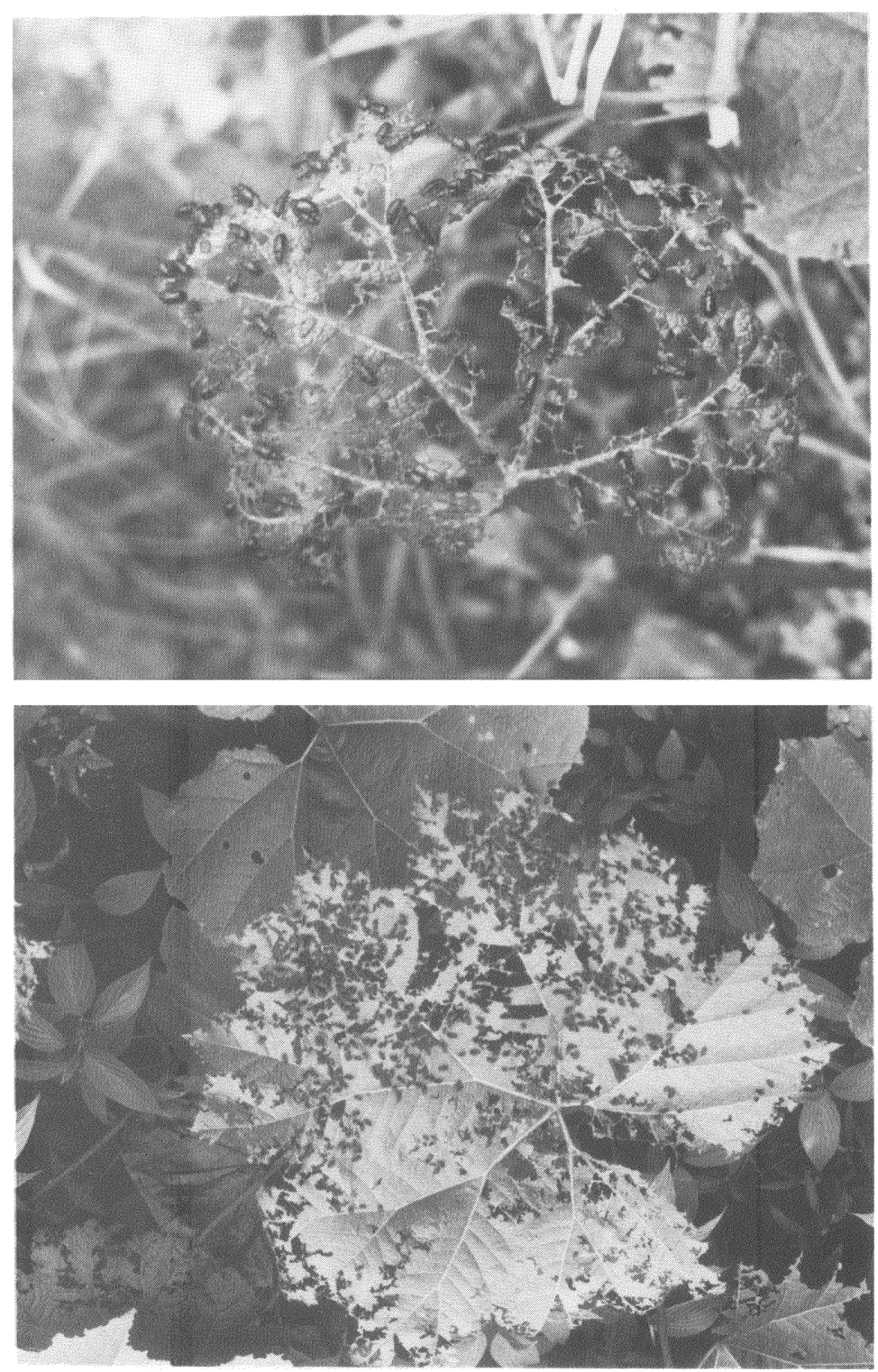

Fig. 2. Adults of $M$. sp. on small (above) and large (below) leaves of Gunnera insignis. 
$0-28.2$ ) (in 13 of 16 pairs the density on the unoccupied leaf was higher, $\mathrm{p}<0.01)$.

Larvae remained on the host plant day and night. Although larval coloration was not aposematic (pale brownish yellow or orange with black head capsule, legs, and bristles), some larvae of both species had a strongly disagreeable taste. Recently moulted third instar larvae (mostly black in color) had little or no taste, but fully grown larvae (mostly orange in color) of $M$. sp. on G. insignis plants produced a delayed but powerful burning sensation. When one entire larva was tasted, the burning began about $30 \mathrm{sec}$ later, and lasted for more than 15 minutes. A larva of $M$. $j$. on a $L$. octovalvis plant and an adult $M$. sp. on a $G$. insignis plant had a similar, though less intense taste (larvae were identified by association with nearby monospecific aggregations of adults).

First instar larvae generally began feeding in a group near eggs from which they hatched, but older larvae did not aggregate as they fed. The average number of $M . j$. larvae per occupied leaf on two L. octovalvis plants was $1.8 \pm 1.8(\mathrm{~N}=57$ leaves with larvae $)$. Early instar larvae of both species usually fed on only the lower layers of the leaf, leaving the upper side intact. Later instars ate entire leaves of Ludwigia spp., but usually left one (usually the upper) side of the much thicker $G$. insignis leaves intact. Larval damage to $G$. insignis leaves was thus easily distinguished from that produced by adults, as in some Altica (Woods 1917, 1918). Larvae on Ludwigia plants which had been stripped of leaves also fed on the cuticle of stems and fruits. Although there was substantial variation, it appeared that $M . j$. larvae tended to feed on leaves lower down on $L$. octovalvis plants.

Larvae left host plants to search for appropriate pupation sites. In nature mature larvae of $M$. sp. (identified as such by heavily damaged Gunnera plants and the absence of Ludwigia or Cuphea plants nearby) were seen crawling on the ground $5 \mathrm{~m}$ from the nearest plant with larval feeding damage; mature $M . j$. larvae (identified by raising them to adults) were found to up to $>1 \mathrm{~m}$ from the base of the nearest $L$. octovalvis.

Active selection of pupation sites was demonstrated experimentally in $M . j$. When offered either rich humus or sandy soil, larvae tended to pupate in humus: 74 vs. 1 adults were raised in two replicas with sandy soil in the central portion, 57 vs. 13 in two replicas with sandy soil on the periphery (ratio of area in center: periphery 
$=1: 2.31, \mathrm{p}<0.001)$. Although their food plants generally grow in sites with waterlogged soil, larvae preferred to pupate in drier soil. When offered either humus soil with water barely standing (approximately $43 \%$ water content by weight) or drier humus soil (approximately $32 \%$ water content by weight), the larvae tended to pupate in the drier soil ( 78 vs. 0 adults in two replicas with the drier soil on the periphery $(\mathrm{p}<0.001)$.

Underground, larvae constructed small, ovoid pupation chambers. The depth of 62 chambers in captivity averaged $1.7 \pm 1.2 \mathrm{~cm}$. The long axis of 56 of 59 chambers was more nearly vertical than horizontal. The chambers were closed on all sides, and the inner walls were relatively smooth, perhaps due to addition of a secretion as in Altica spp. (Woods 1917, 1918). The length of 11 chambers (average $1.05 \pm 0.10 \mathrm{~cm}$ ) was substantially greater than that of the pupae in these chambers (average $0.68 \pm 0.02 \mathrm{~cm}$ ).

Of 59 pupae of $M . j ., 56$ faced more nearly upward than horizontal, 3 were more nearly horizontal than upward or downward, and 0 were more nearly downward. As in Altica spp. (Woods 1917, 1918, Barstow and Gittins 1973), pupae were covered with stiff bristles, presumably to keep the body out of contact with the walls of the chamber. The especially large bristles at the tip of the abdomen might seem designed to support the pupa's weight, but similar enlarged bristles occur in Altica bimarginata, which lies on its dorsum as a pupa (Woods 1917).

Young pupae were orange with black setae, while the legs and heads of $M . j$. pupae about to moult to adults were blue, and the abdomen was swollen and extended directly rearward instead of curling ventrally. The pupal cuticle ripped near the anterior end, and the adult pulled its antennae and legs free as movements of the abdomen pulled the cuticle posteriorly. After freeing itself from the cuticle, the adult beetle extended its hind wings, projecting them posteriorly and ventrally from under the clear elytra. Individuals in captivity (on moist paper towels) braced their middle and hind legs laterally during this stage. Presumably beetles in pupal chambers braced themselves in the upper end of the chamber, thus giving the hind wings room to expand in the lower portion of the chamber. This would explain why pupation chambers were longer than the pupae. Young adults remained underground at least briefly before emerging on the surface. Sex ratios were close to 50:50. 
$48 \%$ of $914 M$. sp. and $42 \%$ of $488 M . j$. raised to adults were males.

Males did not emerge before females, as in some other chrysomelids (Waloff and Richards 1958). Adult females may emerge from pupation with more reserves than males. Thus of 27 survivors of a group of 88 adult $M . j$. which emerged in a container with moist earth and were kept with no food for about 7 days, 3 were males and 24 females $(p<0.001$ compared with overall sex ratio).

\section{Host Plants}

As in many other alticines (Jolivet 1988), both species were oligophagous. They fed on different but overlapping sets of host plants. Adult and larval $M$. sp. occurred on Gunnera insignis (Gunneraceae) (approximately 50-150 aggregations of adults seen, totalling probably 10-25,000 beetles near Rio Hondura, Zurquí, Cerro de la Muerte, Tapantí, and about $40 \mathrm{~km}$ NNW of San José on the road to Puerto Viejo de Sarapiquí), but $M$. $j$. was never seen on this plant. On the other hand $M . j$. but not $M$. sp. adults were common on Ludwigia hexapetala (Hook and Arn.) (Onagraceae) (more than 30 aggregations totalling probably $>10,000$ beetles seen at Rio Reventado, and Rio Barquero near Cartago). Adults and larvae of both species occurred at least occasionally on L. octovalvis (Jacq.) (estimated 100-200 aggregations of adults) and L. peruviana (L.) (estimated 10-20 aggregations of adults) in and near the Universidad de Costa Rica in San Pedro de Montes de Oca, San Antonio de Escazu, Escazu, San Isidro de Heredia, and Cartago; $M$. $j$. was consistently more common than $M$. sp. on L. octovalvis (Table 2). Both species were also found on Cuphea sp. plants (Litraceae), but in monospecific aggregations $(M . j$. on $C$. calophylla Cham. and Schlechtd near Alajuelita about $5 \mathrm{KM}$ E of Escazu, and on $C$. sp. near San Vito de Java, San Antonio de Escazu, and the Universidad de Costa Rica; $M$. sp. on $C$. sp. in Zurquí). Scattered adults of $M$. sp. were seen feeding on Tabachina longifolia (Melostomataceae) adjacent to large aggregations on $G$. insignis near Zurquí, and near San Antonio de Escazu.

The four families of host plant are not closely related, but all are early secondary, weedy species. Ludwigia and Cuphea grow in humid soil, often with slowly moving or standing water, and are 
Table 2. Proportions of $M$. jamaicensis and $M$. sp. in mixed aggregations in the field on $L$. octovalvis plants (all purple individuals were classified as $M$. sp.; some may have been hybrids). An estimated minimum of 50-100 other aggregations of only $M . j$, and 10-30 mixed aggregations were also seen on this plant. $(\mathrm{OCH}=$ Ochomogo, just W. of Cartago; SAE = San Antonio de Escazu; SIH = San Isidro de Heredia; UCR = Universidad de Costa Rica).

\begin{tabular}{llllc}
\hline Date & Site & \multicolumn{2}{c}{ Proportion } & \multirow{2}{*}{ Total } \\
& & $M$. sp. & $M . j$. & \\
\hline 30 V 84 & UCR & .48 & .52 & 40 \\
6 I 84 & UCR & .10 & .90 & 59 \\
1 VI 85 & UCR & .23 & .77 & 65 \\
1 VI 85 & UCR & .27 & .73 & 55 \\
14 VII 85 & UCR & .03 & .97 & 343 \\
26 IX 85 & UCR & .02 & .98 & 172 \\
23 IX 85 & UCR & .13 & .87 & 38 \\
26 IX 84 & OCH & .03 & .97 & 104 \\
VI-VII 83 & SAE & $.65-.12$ & $.35-.88$ & $65-355$ \\
22 II 87 & SJC & .01 & .99 & 411 \\
28 III 87 & SJC & .02 & .98 & 63 \\
30 XII 85 & SAE & .01 & .99 & 150 \\
1 III 86 & SAE & .05 & .95 & 20 \\
8 VI 85 & SAE & .02 & .98 & 129 \\
10 VIII 85 & SAE & .03 & .97 & 29 \\
18 IX 87 & SIH & .80 & .20 & 65 \\
\hline
\end{tabular}

common in roadside ditches carrying effluents from houses in suburban and rural situations. Gunnera and Tabachina differ in being associated with well drained soils rather than swampy substrates, but grow in recently disturbed areas; Gunnera is associated with very high rainfall (Fernandez 1984).

Individual beetles can and probably sometimes do eat more than one food plant in nature. In one case, $M . j$. larvae (identified by association with mono-specific aggregation of adults) occurred in large numbers on plants of L. octovalvis which were nearly stripped of leaves, and in lower numbers on immediately adjacent Cuphea calophylla plants. In another case, a large aggregation of adult $M . j$. which was checked for several days first decimated a long row of L. octovalvis plants, then moved onto (and killed) several small Cuphea sp. plants before disbanding. Adults and larvae of $M$. sp. collected on $G$. insignis fed readily on $L$. hexapetala and L. octovalvis in captivity. 
The nearly complete absence of $M$. sp. on L. hexapetala (3 of 5,000-10,000 beetles), and the complete absence of $M . j$. on $G$. insignis ( 0 of several 10's of thousands of beetles) is probably related to the relative inability of the larvae of these species to develop on these plants (Table 3). In contrast, F1 hybrid larvae matured successfully on both of these species (Table 3). It appeared that $G$. insignis was more "difficult" for both beetle species as well as for hybrid larvae, as larval weight at maturity was lower for all crosses, and development times were longer (Table 1, see also oviposition rates below). Lower larval weights did not, however, generally lead to higher pupal mortality, except in the extreme case of the few small $M . j$. raised on $G$. insignis (Table 3).

\section{Reproductive Behavior}

Females in captivity began to oviposit several days after emerging above ground. Feeding on living rather than recently picked leaves, and in more humid conditions lowered the number of days between first copulation and first oviposition, and raised the rate of egg production during the first days of oviposition (Table 4).

Oviposition rates in the field may be lower. Of ten fieldcaptured female $M . j$. placed on L. octovalvis plants, only $50 \%$ oviposited during the first 24 hours; $30 \%$ took 48-72 hours to oviposit; and $20 \%$ had still not oviposited 17 days later. Data for $12 M$. sp. collected on L. octovalvis were $17 \%$ oviposited in the first 24 hours, $33 \%$ after $24-72$ hours, and 50\% after 3-7 days. The average numbers of eggs laid in these clutches were not high (17.2 \pm 17.0 for $M . j ., 10.8 \pm 8.7$ for $M$. sp.; compare with Fig. 3).

Table 3. Survivorship of Macrohaltica Jamaicensis, M. sp. and cross-specific hybrids raised on three different food plants. $(j .=M$. jamaicensis; $\mathrm{sp} .=M$. $\mathrm{sp}$. $)$ A is the proportion of larvae born which grew to mature larvae; B is the proportion of larvae born which emerged above ground as adults.

\begin{tabular}{|c|c|c|c|c|c|c|c|c|c|c|}
\hline \multirow{3}{*}{\multicolumn{2}{|c|}{$\begin{array}{l}\text { Cross } \\
\text { female male }\end{array}$}} & \multicolumn{3}{|c|}{ Ludwigia hexapetala } & \multicolumn{3}{|c|}{ L. octovalvis } & \multicolumn{3}{|c|}{ G. insignis } \\
\hline & & \multirow[t]{2}{*}{$\mathrm{N}$} & \multicolumn{2}{|c|}{ survivorship } & \multirow[t]{2}{*}{$\mathrm{N}$} & \multicolumn{2}{|c|}{ survivorship } & \multirow[t]{2}{*}{$\mathrm{N}$} & \multicolumn{2}{|c|}{ survivorship } \\
\hline & & & A & B & & A & B & & A & B \\
\hline$j$. & $j$. & 808 & 0.54 & & 565 & 0.95 & 0.9 & 804 & 0.04 & 0.00 \\
\hline sp. $\times$ & sp. & 305 & 0.39 & & 177 & 0.75 & 0.71 & 181 & 0.86 & 0.56 \\
\hline j. $\times$ & sp. & 410 & 0.57 & & 469 & 0.87 & 0.74 & 327 & 0.77 & 0.63 \\
\hline sp. $\times$ & $j$ & & & & 109 & 0.58 & 0.50 & 131 & 0.87 & 0.69 \\
\hline
\end{tabular}


Table 4. Effect of conditions in early life on length of period before oviposition began in female $M$. jamaicensis, and on rate of egg production during the first four days of oviposition. Condition A: female kept on tender leaves of L. octovalvis plant from first day to adult life; Condition B: female kept in petri dish with moist paper towel and supplied with one newly picked leaf of $L$. octovalvis each day; Condition C: as in B but without moist towel. Males were combined with females, allowed a single copulation, then removed 1-2 hrs after copulation ended on the first day of mating. Similar matings were staged a day later, and, in conditions B and $\mathrm{C}$, on each of the following two days. All pair-wise differences are highly significant $(\mathrm{p}<0.001)$ except number of days to first oviposition B vs. $C$, in which $\mathrm{p}<0.01$ ) (Mann Whitney U Test).

\begin{tabular}{lccc}
\hline & \multicolumn{3}{c}{ Condition } \\
\cline { 2 - 4 } & $\mathrm{A}$ & $\mathrm{B}$ & $\mathrm{C}$ \\
\hline Age at first copulation (days) & $7.5 \pm 0.5$ & $9.0 \pm 0.0$ & $8.4 \pm 1.7$ \\
$\begin{array}{c}\text { No. of days from first copulation } \\
\text { to first oviposition }\end{array}$ & $2.4 \pm 0.5$ & $7.6 \pm 0.9$ & $9.6 \pm 2.8$ \\
$\begin{array}{c}\text { No. of eggs laid in first four days } \\
\text { of oviposition period }\end{array}$ & $134.4 \pm 74.9$ & $73.0 \pm 23.1$ & $37.2 \pm 18.5$ \\
$\mathrm{~N}$ (females) & 12 & 21 & 13 \\
\hline
\end{tabular}

Captive female $M$. sp. feeding on $L$. octovalvis laid many more eggs than those feeding on $G$. insignis. Average daily rates for the first 24 days of oviposition by 26 individuals on $L$. octovalvis was 6.32 eggs/female/day (ranges 3.7 to 9.0 for averages for different females); the corresponding numbers for 15 individuals on $G$. insignis was 1.32 (range $0.45-1.80)(\mathrm{p}<0.01$ with Mann Whitney $\mathrm{U}$ Test comparing averages for 11 females on $L$. octovalvis with those for 10 on G. insignis).

Conditions early in adult life also affected male sexual behavior. Male $M . j$. separated from females and kept in two groups of 20-40 in gallon jars within 1-2 days after emerging and fed fresh cuttings of $L$. octovalvis once every 1-2 days all failed to mount and court females when they were 1-2 weeks old. In contrast, 19 of 19 males caged individually in plastic bags on living plants from their first day above ground mounted and courted females, often very assiduously, at the same age.

Both males and females mated repeatedly in captivity. Since females usually discard the spermatophores in which sperm is 

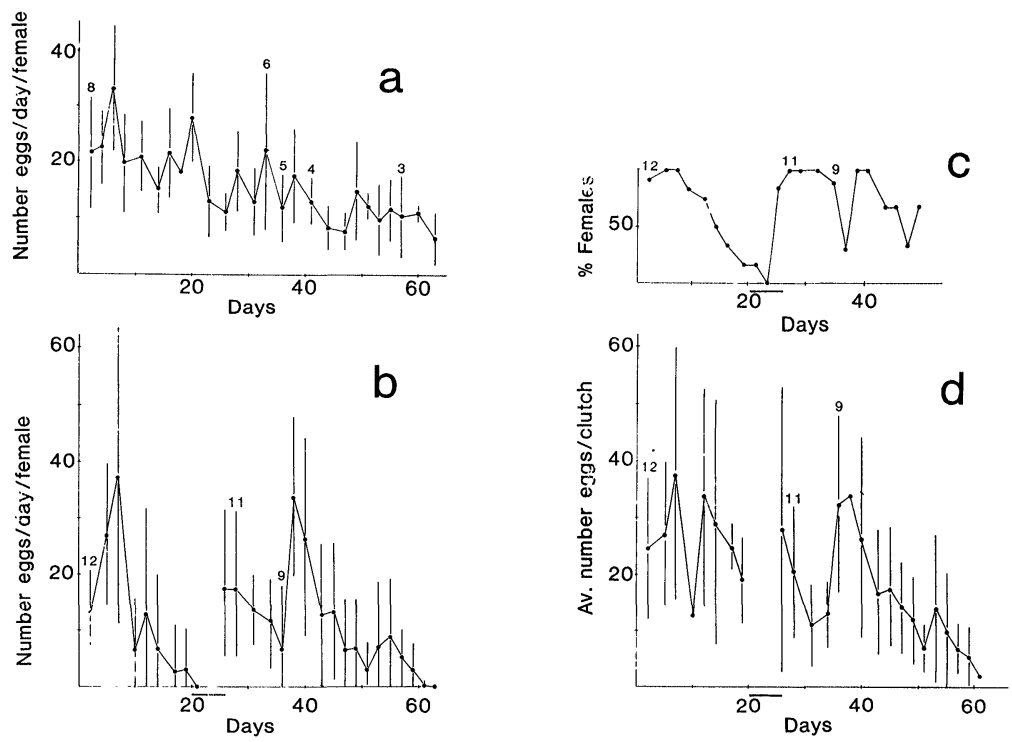

Fig. 3. Changes in numbers of eggs laid vs. female age in $M$. jamaicensis feeding on $L$. hexapetala (a) and L. octovalvis (b-d). a) Eggs produced over approximately two months with continuous access to males (small numbers indicate numbers of females when they changed due to death or loss) (vertical bars are standard deviations). b) Eggs produced after a pair of copulations occurred before the first oviposition, then the female was isolated until day 20 when she was kept with a male for 3 days (horizontal bar) before being isolated again. c) Numbers of females ovipositing during the experiment described in b). d) Numbers of eggs laid during the experiment described in $b$ ).

transferred a few hours after copulation (Eberhard and Kariko in prep.), it was possible to deduce the number of times a female which had been kept captive with a male had been inseminated by counting the numbers of spermatophores in her petri dish. Pairs of $M$. $j$. mated more often than did $M$. sp. pairs (Table 5). Interspecific crosses gave results typical of the males rather than females (Table 5), so the differences between species were apparently due to differences between males.

Females probably mate with many different males in the field. The beetles in many pairs seen at night in Aggregation I separated in the morning. When 34 individually marked female $M . j$. and an 
Table 5. Numbers of spermatophores found in petri dishes with different pairs of Macrohaltica beetles. Females were kept isolated from males for the first 9-10 days of their lives. Then each female was kept for 8-10 days with a given male ("first male"). After this time, the male was replaced with a male of the other species ("second male"). Crosses were the following: A - female $M$. $j$. first with male $M$. sp. then with male $M . j . ;$ B - female $M$. $j$. first with male $M$. $j$., then with male $M$. sp.; C - female $M$. sp. first with male $M$. $j$., then with male $M$. sp.; D - female $M$. sp. first with male $M$. sp., then with male $M$. $j$. All differences between first and second male are significant $(\mathrm{p}<0.05)$ except for $\mathrm{D}$. All differences between $M . j$. males and $M$. sp. males within first male category are significant $(\mathrm{p}<0.001)$; the differences in second male data between A compared with B and D are significant $(\mathrm{p}<0.01)$, but those between D compared with B and C are not (all tests with MannWhitney U Test).

\begin{tabular}{lccc}
\hline & & First male & \multicolumn{1}{c}{ Second male } \\
\cline { 3 - 4 } & Female & spermatophores/male/day & spermatophores/male/day \\
\hline A. & $M . j$. & $2.12 \pm 0.50(\times M . j)$. & $0.52 \pm 0.37(\times M . \mathrm{sp})$. \\
B. & $M . j$. & $0.79 \pm 0.55(\times M . \mathrm{sp})$. & $1.57 \pm 0.80(\times M . j)$. \\
C. & $M . \mathrm{sp}$. & $0.81 \pm 0.53(\times M . \mathrm{sp})$. & $1.44 \pm 0.76(\times M . j)$. \\
D. & $M$. sp. & $1.73 \pm 0.45(\times M . j)$. & $1.51 \pm 0.70(\times M . \mathrm{sp})$. \\
$\mathrm{N}=10$ females for each cross & \\
\hline
\end{tabular}

equal number of males were placed in a cloth cage on a $L$. octovalvis plant and checked each evening (9-12 PM), the same male was riding the female in successive evenings in 16 cases, different males rode on successive evenings in 16 cases, a male was riding on one evening but the female was alone on the next in 16 cases, and a female was alone on one evening but paired on the next in 10 cases. The longest certain pairing was 3 days (since marks were rapidly lost, some cases were uncertain).

A single spermatophore represents only about $1 \%$ of the male's weight (Eberhard and Kariko in prep.), and spermatophores were apparently not especially costly for males. When males were kept without food they continued to produce substantial numbers of spermatophores. Fifteen male $M . j$. were kept in a separate cage for at least 14 days on a branch of a potted L. octovalvis. During this period each male participated in 0-8 matings, during which he spent 2-6 hours with a female in a petri dish with a moist paper towel, and was then returned to plant. Each male was then placed with a virgin, 7-21 day-old female in a petri dish with a moist 
paper towel but without food for three days. The number of spermatophores found at the end of the first day $(a v .=2.9 \pm 0.9)$ did not differ significantly from that at the end of the second (av. = $3.1 \pm 1.0)$. The number decreased slightly on the third day to an average of $2.4 \pm 0.7$, which was similar to rates of spermatophore production when field-caught males were kept with females and fed freshly cut leaves $(a v .=2.1 \pm 0.5-$ Table 5) $(\mathrm{p}<0.024$ comparing each male on second vs. third days of the experiment using the Mann Whitney U Test).

Females apparently needed to mate repeatedly to sustain egg production. Female $M . j$. kept continuously with a male showed a slow, continuous decline in the rate of oviposition over a period of about 60 days (Fig. $3 \mathrm{a}$ ). In contrast, when $12 M . j$. females which had mated twice (on the seventh and eighth days after they emerged above ground) were caged on potted L. octovalvis plants without access to further males, they ceased to oviposit in about a third of this time (after 20 days), and then resumed oviposition when allowed to mate again by being caged for three days with a male (Fig. 3b). Each female probably mated at least 5-10 times each during the second mating period (see above). The egg production by nine females was higher during the first 21 days of this second oviposition period (av. $=369 \pm 104 \mathrm{eggs} / \mathrm{female}$ ) than in the first 21 days of the first oviposition period (av. $=246 \pm 103$ eggs/female), despite the expectation that egg production would decrease with the female's age (Fig. 3a; see also Waloff and Richards 1958), (totals for 8 of the 9 females were greater in the second period $-\mathrm{p}<0.045$ with Signs Test). Reductions in egg production resulted from a combination of lower numbers of females ovipositing (Fig. 3c), and smaller clutches (Fig. 3d). The spermathecae of two isolated females which had ceased to oviposit had only small accumulations of sperm, in contrast to the thick helix of sperm seen in the spermathecae of females from the field (Eberhard and Kariko in prep.), so lack of sperm may have been involved.

\section{Defensive Behavior}

Although adults of both species have enlarged hind femora, they differed from many other alticines in not making long jumps when disturbed (e.g. Furth 1988). Instead they only hopped or lurched 
forward when disturbed, allowing themselves to fall. They often seized a leaf or stem on the way down before reaching the ground. Larvae also reacted to disturbance by falling from the plant, and curled when they reached the substrate below. When held in the fingers, adults usually regurgitated a dark-colored fluid from the mouth and/or a clear liquid from the tip of the abdomen.

Adult $M$. sp. were apparently distasteful to three species of lizard. Two Anolis bipuratus, three Sceloporus malachitious, and two Gerhonotus monticola were offered $M$. sp. beetles; in all cases the lizard seized the beetle in its mouth, then spit it out.

Aggregations of Adults

Adults of both species usually occurred in aggregations which ranged up to more than 5000 individuals on a single plant or several neighboring plants. Usually there were slightly more males than females in an aggregation: in nine aggregations of $M$. sp. of more than 20 beetles, the ratio of male/female averaged $1.13 \pm 0.18$ (total of 975 beetles, differ from 1:1 $\mathrm{p}<0.01$ ); in seven similar aggregations of $M . j$. the average ratio was $1.27 \pm 0.49$ (total of 738 beetles, differ from 1:1 $\mathrm{p}<0.01)$. This bias was probably not due to the sex ratio at birth, which was slightly skewed toward females (above). In both species most aggregations contained both feeding and mating individuals (e.g. Fig. 2). A few aggregations had mainly reproductively inactive beetles, which fed little or not at all; these will be discussed separately.

Feeding Aggregations

In both species it was sometimes possible to "track" a feeding aggregation by locating heavily damaged leaves of $G$. insignis (M. $\mathrm{sp}$ ) or a series of partially or completely stripped $L$. octovalvis plants along a ditch. Some trails of $M$. sp. damage included both adult damage (Fig. 2), and damage by larvae to nearby leaves. The longest such trails were $>30 \mathrm{~m}$ in both species, and included up to 10-20 different plants.

At night the beetles in one mixed species feeding and mating aggregation (Aggregation I) were essentially motionless, apparently immobilized by low temperatures. Many were in pairs, with the male riding on the female's dorsum. In the morning most beetles remained tightly grouped until direct sunlight fell on them, 
then began to walk about. As the day advanced, the beetles became more active, and the aggregation less concentrated. Many malefemale pairs separated, and beetles groomed, walked back and forth on the plant, and walked or flew onto nearby plants. Individuals of $M$. sp. moved away from the night-time cluster more slowly than those of $M . j$. For example, at 8:30 AM of the morning of 30 June, $43 \%$ of the 74 more or less immobile beetles in the central cluster were $M$. sp; at $11 \mathrm{AM}, 61 \%$ of the 36 remaining beetles were $M$. sp. $(\mathrm{p}<.05)$.

As the day wore on, new clumps of beetles formed, some on food plants and others on other species; clumps were nearly always in shaded sites during the earlier part of the day. Some of these aggregations dissolved as the day passed, and eventually the beetles accumulated on the host plant where the group would pass the next night. If the previous evening's host plant had not been consumed, some beetles stayed there, and the aggregation often reformed there the next evening. Sometimes the aggregation split into subgroups on different host plants on one night, then rejoined in a single group later.

The behavior of $M$. sp. aggregations on $G$. insignis leaves was different. There was usually little flight activity near aggregations even during the heat of the day. Judging by the freshness of damage to leaves, aggregations probably moved between plants much less often. The difference is presumably related to the much larger leaves of $G$. insignis (average $>1 \mathrm{~m}$ in diameter), and perhaps to slower rates of feeding. These leaves (especially young ones) were occasionally completely stripped by adults, but more often the aggregation moved on before more than half of the leaf surface had been consumed (Fig. 2).

Some feeding aggregations apparently consisted largely of newly emerged adults, presumably in the vicinity of their pupation sites. No aggregation of this sort was studied in detail, but some aggregations of both species had few pairs and contained predominantly soft-bodied individuals (recent emergence from under ground was confirmed in one $M$. sp. aggregation by finding that the males' genitalia were light in color). Two aggregations of mainly soft-bodied $M$. $j$. were found at sites where $L$. octovalvis plants had been completely stripped several weeks previously (judged by freshness of plants). 
Non-feeding Aggregations

Each of 15 randomly selected $M . j$. females in Aggregation II had very large fat bodies, but none had eggs more than $0.7 \mathrm{~mm}$ long (mature eggs are about $1.2 \mathrm{~mm}$ long). There was also a low frequency of pairs (males mounted on females) in this aggregation. Only $17 \%$ of 426 beetles were paired on the night the aggregation was collected, and approximate counts on 3 earlier nights gave even lower percentages; $43 \%$ of the 352 unpaired beetles in this aggregation were females.

Aggregation III of $M$. sp. was probably also reproductively inactive. The beetles did not feed during the three days they were observed (they were on low grass in a pasture), and few if any pairs formed at night (the beetles were piled on each other in some portions of the aggregation, making it impossible to count pairs).

Similar lack of ovarian development was seen in 10 randomly selected females of $M$. sp. collected 22 Feb. 1992 from Aggregation IV, which was also on grass, with Tabachina plants $<10 \mathrm{~m}$ away. This aggregation was near the top of a steep ridge on the side of a mountain (Pico Blanco) (the other non-feeding aggregation (III) of $M$. sp. was also near the top of a ridge.).

Aggregation IV was observed over a longer period of time than the others. When first discovered on low grass at the edge of a road (22 Feb. 1992) it consisted of an estimated total of 1,000-2,000 M. sp. in several tightly packed clumps. When next seen (18 March), about $30 \mathrm{~m}$ from the first site (presumably the same aggregation beetles were not marked until $20 \mathrm{March}$ ), an estimated $3,000-10,000$ beetles were dispersed in herbacious growth along 3-4 $\mathrm{m}$ on the other side of the road. Observations just before sunset and two nights later showed that the beetles remained dispersed. A total of 300 beetles were marked along about $2 \mathrm{~m}$ of the roadside on 20 March, and marked beetles were seen over the next 75 days. Sightings of marked individuals occurred along approximately $60 \mathrm{~m}$ of the roadbank. Estimated numbers of beetles ranged from 200-300 to several thousand (at last sighting on 3 June, there were an estimated 1,000-2,000 individuals). These estimated sizes of this aggregation are minima, as the thick vegetation and the possibility that some beetles had moved away from the edge of the road meant many beetles could easily have been missed on any given visit. On the visit following marking (22 March), 9 of 300 beetles counted had marks. Assuming complete mixing, no loss of 
marks, and no arrivals of unmarked beetles, this ratio gives an estimated total of approximately 10,000 beetles in the aggregation on 20 March. Since marks are often lost (see below), this may be an overestimate, but direct estimates gave approximately the same size.

Aggregation IV lasted at least 97 days. The beetles occurred on a variety of plant species, but were only occasionally seen feeding, on Tabachina longifolia. In none of the first 11 visits were any male-female pairs seen (through 23 April - each visit was during the daylight hours except on $20 \mathrm{March}$ ). The first pair was seen on 26 April in a group of about 600 individuals. Pairs remained rare until 16 May (four more visits), when there were more than 10 pairs in a group of 200-300 individuals, and on 21 May there were 25 pairs in a group of 85 individuals. Pairs were again relatively rare ( $<10$ pairs among about 1,000 beetles) on 28 May.

\section{Movements of Aggregations}

We were unable to understand how the beetles in aggregations (both feeding and non-feeding) coordinated their movements. Some beetles in Aggregations I and III walked from one aggregation site to the next, but most flew. The majority of flights were $<1$ m. In Aggregation III most flights were in the direction in which the mass of beetles was moving, but this was not true in Aggregation I. Both males and females in Aggregation I also initiated apparent long distance dispersal flights, flying directly upwards and away until they were lost from sight at a distance of at least 7 $\mathrm{m}$. Both males and females occurred on the periphery of aggregations which were on the move. A sample of the periphery of a very large (probably several thousand) feeding aggregation of $M$. sp. which was moving included 19 males and 29 females. A similar collection on the periphery of the non-feeding Aggregation II (of $M . j$.) yielded 13 females and 11 males.

The distances between nightly aggregation sites were 1-2 $\mathrm{m}$ for Aggregations I-III. Individual beetles probably travelled much longer distances.

Behavior within a Feeding and Mating Aggregation

There were small differences in the behavior of $M$. sp. and $M . j$. in Aggregation I. During nightly checks each beetle's position was classified as "central" (near or in the central mass of beetles where 
beetles were literally piled on each other), or "peripheral." Both male and female $M$. sp. were more likely to be in the central group than were individuals of $M . j .: 78 \%$ of 137 male sightings and $81 \%$ of 286 female sightings of $M$. sp. were in the central group; corresponding figures for $M . j$. were $58 \%$ of 487 and $52 \%$ of 232 (differences between species $\mathrm{p}<.001$ for both sexes; differences between sexes of the same species not significant $p>.4$ ).

Resightings of marked individuals in Aggregation I suggested substantial rates of turnover in membership. For instance, 111 of 118 beetles $(94 \%)$ had marks after the visit on the evening of 30 June, but only 51 of 90 beetles (57\%) found the next night had marks. Averages of the "before and after" percentages were $88 \pm 4 \%$ before and $57 \pm 21 \%$ after, suggesting that about $30 \%$ of the beetles in the aggregation were new each night. Marks on caged beetles were frequently lost, however. Of 27 beetles marked with multiple dots in the afternoon, $37 \%$ had lost at least some of their marks by the evening of the next day. Thus turnover in Aggregation I was probably less than $30 \%$. Nevertheless, substantial changes did occur. For instance at the end of the visit on the evening of 1 July, 78 of the 98 beetles present were marked; at the beginning of the visit the next night, 97 beetles (of 134) had marks. Numbers of beetles varied from night to night by up to $50 \%$, and the relative numbers of the two species also varied, so that what was at first a nearly 50:50 mix came to be dominated by $M . j$. (Fig. 4).

Unmarked recruits to this aggregation were more often females than males. In the period 30 June-9 July, 215 (57\%) of 377 unmarked beetles found in pairs were females, while during the same period $529(48.6 \%)$ of all sightings of marked beetles in the aggregation were females $(\mathrm{p}<.001$ with Chi Squared Test). This difference may be an underestimate, since the total sightings of males probably underestimates true frequency of males because solitary individuals (some of which were not sexed for lack of marks) probably tended to be males (see below). Unless females either lost their marks much more often than males, or unmarked females failed to pair much more often than marked females, the conclusion is that females joined this aggregation at greater rates than males. 


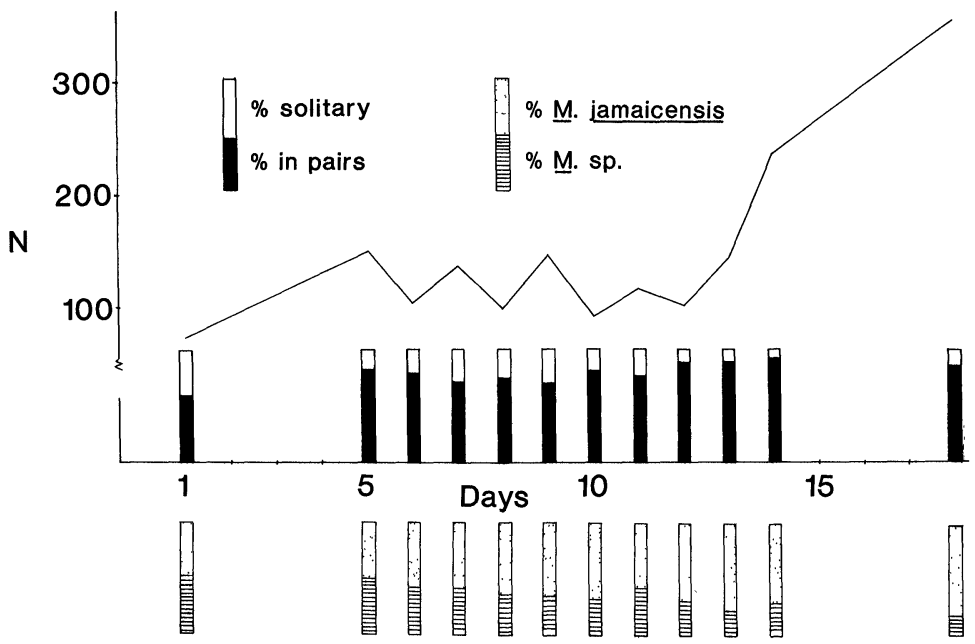

Fig. 4. History of Aggregation I during 18 days, including numbers of beetles present each night (line), fraction of beetles in pairs (solid bars), and species composition of the aggregation (dotted and cross-hatched bars).

\section{Pairing}

Males frequently rode on females' backs both prior to and following copulation. Riding males courted and attempted intromission at irregular intervals. In the descriptions below, pairing includes all males riding on females.

Cross-specific pairs were less frequent than expected if pairing was random, even when the difference in the tendencies of the two species to be in the central area of the aggregation was taken into account. Thus of 222 sightings of paired female $M$. sp. in the central area on 13 nights, $32 \%$ involved a $M$. sp. male, while only $9 \%$ of the 105 sightings of paired $M . j$. females in the central portion on the same evenings involved $M$. sp. males $(\mathrm{p}<0.001)$. Corresponding data for the periphery were $19 \%$ of 59 sightings of paired $M$. sp females and $5 \%$ of 105 sightings of paired $M$. $j$. females $(\mathrm{p}=0.004)$.

Male $M$. sp in Aggregation I were more often seen unpaired than male $M . j$. on the same evenings (30\% of 137 sightings vs. $14 \%$ of 460 sightings respectively, $\mathrm{p}<0.001$ ), even though $M$. sp. females were sighted more often (291 vs 214 ) and the percentage 
of unpaired female $M$. sp. was slightly higher (3.4\% vs. $1.9 \%)$. Male $M . j$. in the center were more frequently paired than those on the periphery ( $88 \%$ vs. $66 \%$; p<.001). Male $M$. sp. showed a similar, though not significant trend to pair more frequently in the center $(64 \%$ vs. $51 \% ; .2>$ p $>.1)$. Percentages of paired individuals varied from night to night in the aggregation (Fig. 6).

Percentages of beetles in pairs varied greatly between aggregations. In the mixed Aggregation I the average was $78 \pm 10 \%$ on 12 nights, and in this aggregation most of the unpaired individuals of known sex were males (av. $=85 \pm 16 \%$ on 11 nights with a total of 120 observations of unpaired marked individuals). Thus in Aggregation I nearly all female beetles were paired each night. Pairing was less frequent in some aggregations. In ten aggregations of $M$. sp. near Zurquí on 29 Oct. 1989 (numbers of beetles/aggregation ranged from 50 to 250), five aggregations did not have a single pair, three (with 56,75 , and 100 beetles) had only $1-3$ pairs, and two (with 77 and 135 beetles) had 28 and 29 pairs respectively. Substantial variation in frequency of pairing also occurred in $M . j$. aggregations.

\section{Parisitism by Flies}

The sarcophagid Chrysagria alticophaga Lopes and Achoy parasitizes third instar larvae of $M . j$. (Lopes and Achoy 1986). In nine different collections of third instar larvae from $L$. octovalvis in the field, the percentage of parasitism averaged $39 \pm 21 \%$, and undetermined numbers of flies emerged from each of three other collections of larvae from this food plant. In contrast, not a single fly emerged from more than six groups totalling $>500$ larvae of $M$. sp. collected from $G$. insignis.

A tachinid fly, probably Strongygaster sp., was raised from ten $M$. sp. collected on G. insignis near Zurquí, and (apparently the same species) from a $M . j$. collected near San Vito. No flies were raised from many (one hundred or more) adult $M . j$. collected near San José. A single larva emerged to pupate from each adult beetle; parasitism was fatal for the beetle.

\section{Parasitism by Fungi}

Adult $M$. sp. on G. insignis plants often had growths of two species of laboulbenial fungi, one on their antennae, and the other 
on the elytra and other body parts. Only the species apparently limited to the antenna was seen on $M . j$. in the field. The other species was apparently associated with more humid conditions. Individuals of $M . j$. kept in a moist plastic bag with infected $M$. sp. on a $L$. octovalvis plant also developed growths of this fungus. The most heavily infested individuals were $M$. sp. collected on $G$. insignis at the most humid site (near Zurquí), where beetles carrying $>100$ fruiting bodies were not common.

The species of fungus on the antennae seemed to attack both sexes of both species of beetles with equal facility. Thus in one mixed aggregation on L. peruviana in San Pedro (collected 14 Sept. 1992), 39\% of $33 M . j$. and $33 \%$ of $42 M$. sp. had fungal fruiting bodies on their antennae; corresponding frequencies were $33 \%$ of 43 males and $39 \%$ of 33 females.

Rates of infestation varied between sites. Thus while $93 \%$ of 29 $M$. sp. beetles at Zurquí had fungi on their elytra, none of $42 M$. sp. near the Universidad de Costa Rica had such fungi. In a sample of $26 M$. sp. from a diapausing aggregation above San Antonio de Escazu (Aggregation IV) collected at the end of the dry season (31 May 1992), 95\% had fungi on their antennae, but none had fungi on the rest of their bodies.

Presumably the fungi caused little damage to the beetles (Balazuc 1988), though occasionally fruiting bodies occurred on the ventral surfaces of tarsomeres, and must have caused some difficulty in maintaining footholds.

\section{DisCUSSION}

The two species of this study (as well as an additional Macrohaltica species from Colombia - Eberhard unpub.) are unusual in forming aggregations, sometimes quite tightly grouped, of up to several thousand individuals. Altica adults occasionally occur in small groups (e.g. Phillips 1977a found A. lythri in the spring in groups of 6-12 and occasionally up to 40 beetles, and groups of $A$. oleracea were smaller; Baker et al. 1972 mention a "tendency to aggregate" in Haltica carduorum). The function or functions of the aggregations are not clear. Phillips (1977a) and Baker et al. (1972) proposed that they serve to bring males and females together. The slightly larger numbers of males in most aggregations of $M . j$. and $M$. sp., and the apparently greater turnover of females than males 
in Aggregation I are in accord with this idea. Some aggregations, however, had little or no mating activity, and females had undeveloped ovaries, so this cannot be the only function. Another possible function could be to overwhelm the defensive responses of food plants by attacking en mass. This explanation cannot easily account for the non-feeding aggregations found far from food plants. A further possibility is that the metallic colors of these beetles are aposematic, and that aggregations make this signal more obvious. These possible functions are not mutually exclusive.

Data on beetles marked with paint or with fungal growth permit glimpses of their movement patterns. At least some aggregations (Aggregation I) showed substantial rates of turnover in membership. Some beetles which had left this aggregation subsequently returned, raising the possibility that individuals may circulate between different aggregations. The general failure of $M$. sp. with heavy loads of fungi (typical of beetles near Zurquí) to appear at other sites (the farthest sighting was near San Isidro de Heredia, approximately $4 \mathrm{~km}$ away) suggests that longer distance movements may be rare (at least in this species, and of those individuals (older?) with large accumulations of fungi).

Some of the differences between the behavior of $M$. sp. and $M$. $j$. adults within a feeding aggregation may be related to differences between food plant species. Unmixed aggregations of $M$. sp. on the very large $G$. insignis leaves (Fig. 2) usually take many days (probably on the order of a week) to move on to another leaf. On the other hand, aggregations of $M . j$. on Ludwigia spp. can completely destroy small plants in a day or less, and are thus more often obliged to move on. The greater tendency of $M . j$. in a mixed aggregation to move away from the center may be related to this difference.

Some non-feeding aggregations, in which females had only weakly developed ovaries and the beetles were not soft and recently emerged, suggest that both species may undergo reproductive diapause, as occurs in some temperate zone chrysomelids (e.g. Waloff and Richards 1958). Most of the food plants (except $T$. longifolia and $G$. insignis) are somewhat seasonal, with reduced growth and population sizes during the dry season in most sites. Perhaps poor feeding soon after emergence above ground, which we have shown to inhibit ovary development in females and sexual 
behavior in males, causes beetles to enter reproductive diapause. Such feeding regimes probably occur in nature when adults emerge at sites where aggregations of adults and larvae have destroyed the food plants. Diapause is probably facultative. We found groups of mature larvae feeding on L. octovalvis plants late in the dry season (29 April 1992), and aggregations of $M$. sp. occur on $G$. insignis year round.

It is clear that even for $M$. sp., the plant $G$. insignis is relatively "difficult." Larvae raised in captivity took 1.6 times longer to mature, and at maturity weighed on average only $71 \%$ as much as larvae of the same species raised on L. octovalvis. Females of $M$. sp. laid on average 4.8 times more eggs when fed L. octovalvis than when fed G. insignis. Possible compensating advantages of $G$. insignis are that it is relatively non-seasonal, and grows in cooler climates (i.e. it could have served as a refuge during glaciations).

Although $M . j$. and $M$. sp. are interfertile, producing hybrids which are also fertile (R. Achoy, unpub.), and although cross-specific male-female pairs are common in nature, there are several reasons to believe that the two forms represent distinct species: male genitalia differ in form (Eberhard and Achoy in prep.); an elytral carina is present in females of $M$. sp. but is less pronounced in those of $M . j$. (W. Eberhard unpub.); abilities to develop on different species of food plant are different (this study); male-female pairs tend to be conspecific in mixed aggregations (this study); clustering behavior within an aggregation differs (this study); male copulation behavior differs (Eberhard and Kariko in prep.); and offspring of females which have mated with both types of males tend to be fathered by the conspecific male (Eberhard and Ugalde in prep.). The beetles' preference for highly disturbed habitats makes it impossible to determine whether or not these species evolved in isolation and have only recently come into contact due to the extensive human modification of their habitats.

\section{SUMMARY}

The ranges of two interspecifically fertile species of Macrohaltica beetles overlap in central Costa Rica. Some species of food plant were used by both species, others by only one. The two species differed in their abilities to develop on different food plants. Adults of both beetle species tended to occur in large 
aggregations. Feeding and mating were common in some aggregations, while in others beetles were in apparent reproductive diapause. Beetles in mixed aggregations tended to pair with conspecifics, but many cross-specific pairs also occurred. Although aggregations moved slowly from one host plant to another, membership within at least some aggregations showed substantial turnover. Other aspects of the beetles' natural history, including oviposition behavior, defensive behavior, development and behavior of immatures, dipterous parasites, and fungal infections of adults are also described.

\section{ACKNOWLEDGEMENTS}

We thank David Furth, J. Santisteban, S. L. Shute, and Richard White for beetle identifications and other helpful information, Peter Dobbler for help with the fungi, Mahmut Sosa for observations of lizards, Rafael Lucas Rodriguez for specimens, and Jorge Gomez Laurito and Peter Raven for plant identifications. Fernando Cortéz granted permission to study beetles in Parque Nacional Braulio Carrillo. JU was supported by an Exxon Fellowship from the Smithsonian Tropical Research Institute. The Vicerrectoría de Investigación of the Universidad de Costa Rica and STRI also provided financial support.

\section{Literature Cited}

BAKer, C. R. B., BlackMAN, R. L., AND Claridge, M. F.

1972. Studies on Haltica carduorum Guerin (Coleoptera, Chrysomelidae), an alien beetle released in Britain as a contribution to the biological control of creeping thistle, Cirsium arvense (L.) Scop. J. Appl. Ecol. 9: 819-830.

BALAZUC, J.

1988. Laboulbeniales (Ascomycetes) parasitic on Chrysomelidae. p. 389-398 in P. Jolivet, E. Petitpierre and T. H. Hsiao (eds.) Biology of Chrysomelidae. Kluwer Academic Publ.

BALSBAUGH, E. U. AND HAYS, K. L.

1972. The leaf beetles of Alabama (Coleoptera: Chrysomelidae). Bull. Agric. Expt. Sta. Auburn Univ. 441: 1-223.

BARstow, D. A. AND GitTins, A. R.

1973. Descriptions of the life stage of Altica bimarginata Say (Coleoptera: Chrysomelidae). J. Kans. Ent. Soc. 46: 500-510.

FERNANDEZ, D.

1984. Estudio anatómico y morfológico de Gunnera insignis (Oerst.) A. DC. Rev. Biol. Trop. 32: 197-202. 
JOLIVET, $\mathrm{P}$.

1988. Food habits and food selection of Chrysomelidae. Bionomic and evolutionary perspectives. p. 1-24 in P. Jolivet, E. Petitpierre and T. H. Hsaio (eds.) Biology of Chrysomelidae. Kluwer Academic Publ.

King, A. AND SAUnders. J.

1984. Las plagas invertebradas de cultivos anuales alimenticios en América Central. Overseas Dev. Administ. London 1-182.

LeSAGE, L.

1990. Description of a new Canadian species of Altica feeding on birch (Coleoptera: Chrysomelidae, Alticinae). Can. Ent. 122: 1229-1234.

LOPES, H. DE S., AND ACHOY, R. M.

1986. On Chrysagria (Diptera, Sarcophagidae) with descriptions of two new species, one of them living on the larvae of Altica sp. (Coleoptera, Chrysomelidae). Rev. Brasil. Biol. 46: 273-276.

PhILLIPS, W. M.

1977a. Observations on the biology and ecology of the chrysomelid genus Haltica Geoff. in Britain. Ecol. Entom. 2: 205-216.

1977b. Some aspects of the host plant relations of the chrysomelid genus Haltica with special reference to Haltica lythri. Ent. exp. appl. 21: 261-274.

1978. Sensilla types from the ovipositor of the flea beetle Altica lythri (Coleoptera: Chrysomelidae). Ent. exp. appl. 24: 399-400.

1979. A contribution to the study of species relations within the chrysomelid SCHERER, G. genus Altica Muller in Britain. Zool. J. Linn. Soc. 66: 289-308.

1969. Die Alticinae des Indischen Subkontinentes. Pac. Ins. Monogr. 22: $1-251$.

WALOFF, N. AND RICHARDS, O. W.

1958. The biology of the chrysomelid beetle, Phytodecta olivacea (Forster) (Coleoptera: Chrysomelidae). Trans. Roy. Ent. Soc. Lond. 110: 99-116.

Woods, W. C.

1917. The biology of the alder flea-beetle. Maine Agric. Expt. Sta. 265: 249-284.

1918. The biology of Maine species of Altica. Maine Agric. Expt. Sta. 273: 149-204. 

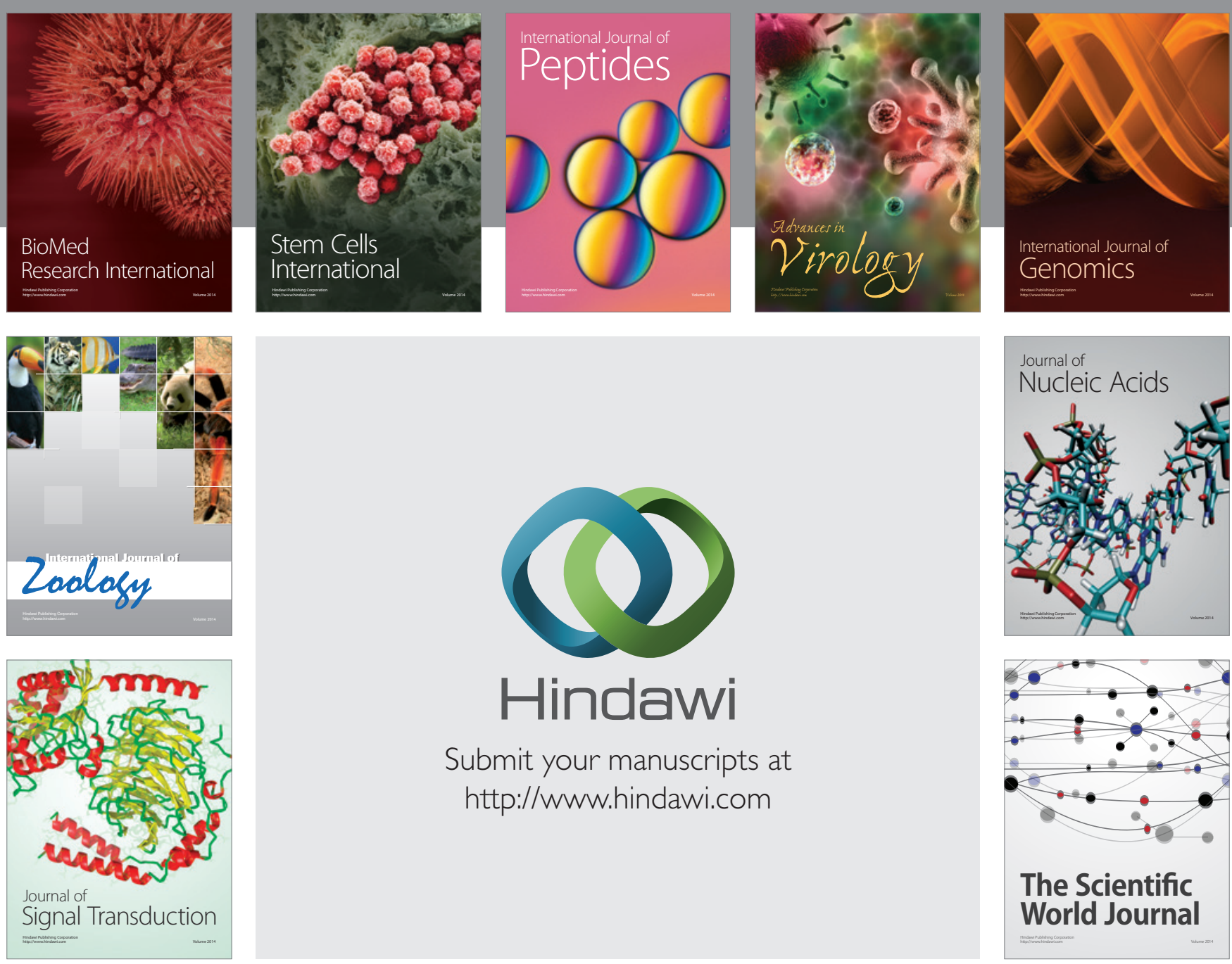

Submit your manuscripts at

http://www.hindawi.com
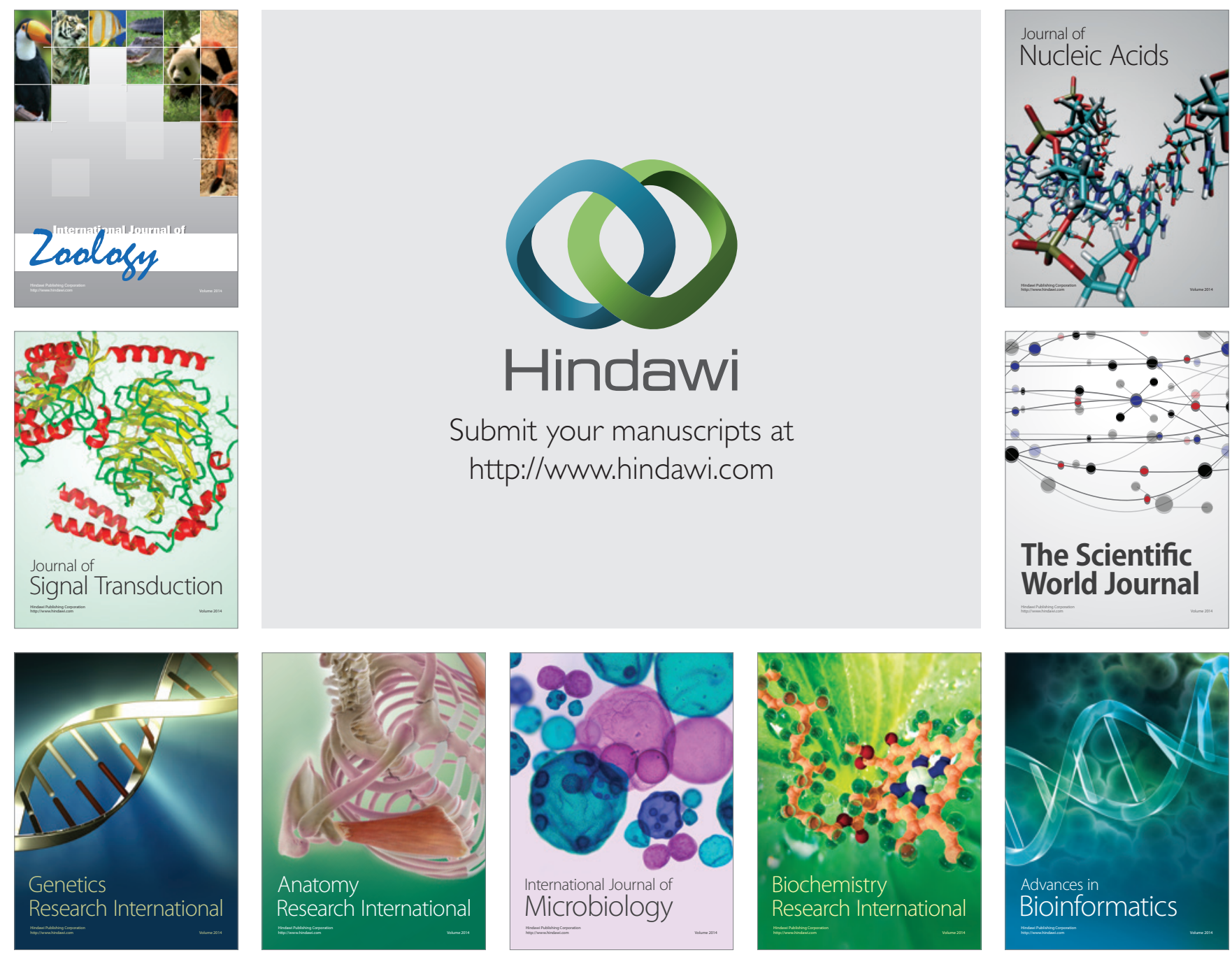

The Scientific World Journal
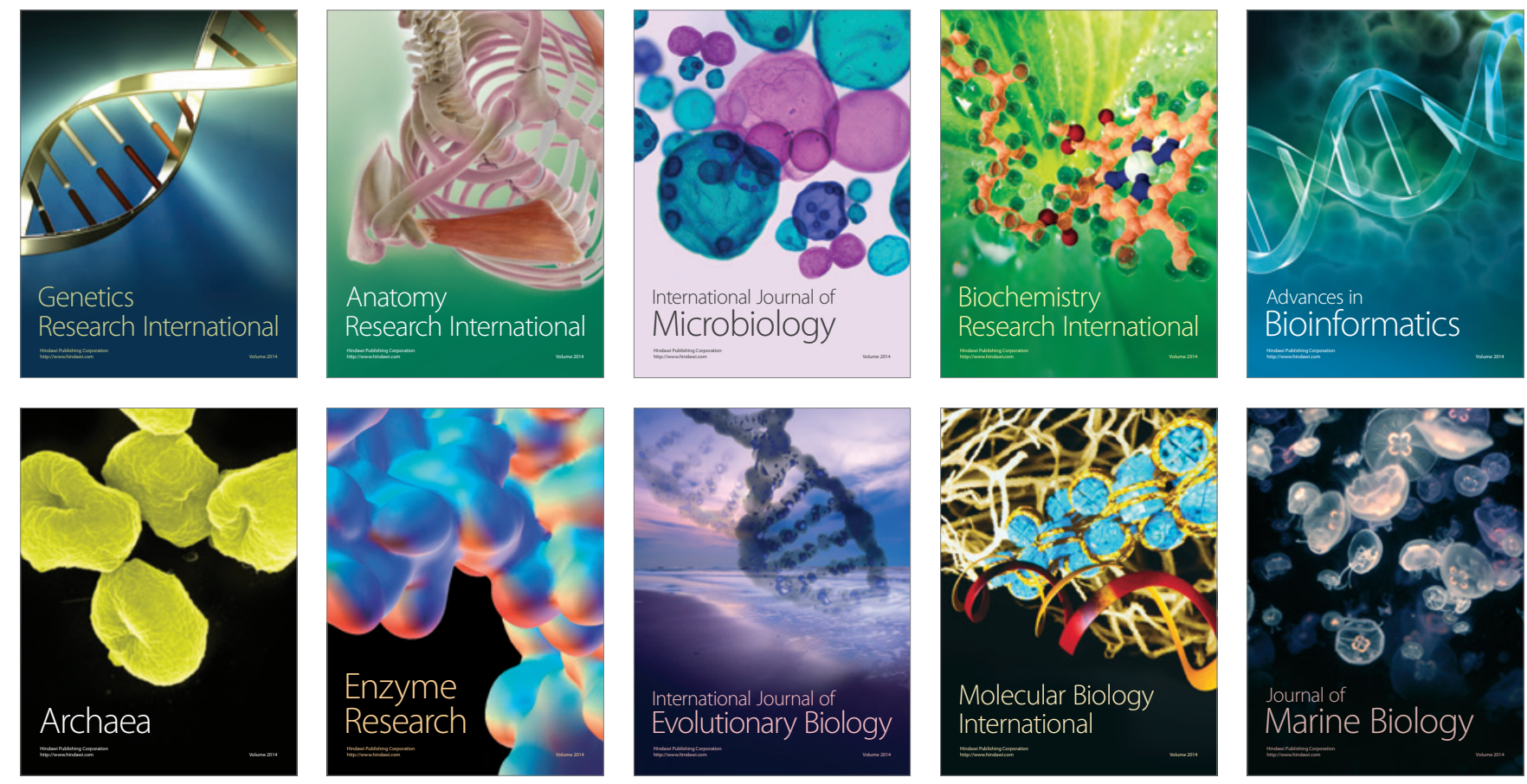